\title{
ORIGINAL
}

\section{ACCIDENTES CON EXPOSICIÓN A MATERIAL BIOLÓGICO CONTAMINADO POR VIH EN TRABAJADORES DE UN HOSPITAL DE TERCER NIVEL DE MADRID (1986-2001)}

Aurelia García de Codes Ilario, José Ramón de Juanes Pardo, $\mathbf{M}^{\mathrm{a}}$ del Pilar Arrazola Martínez, Felisa Jaén Herreros, $M^{a}$ Inmaculada Sanz Gallardo y Emilia Lago López

Servicio de Medicina Preventiva. Hospital Universitario «12 de Octubre». Madrid.

\section{RESUMEN}

Fundamento: La contaminación por el virus de la inmunodeficiencia humana (VIH) es un riesgo ocupacional para los profesionales sanitarios accidentados contaminados con sangre positiva al VIH. El objetivo de nuestro estudio es describir las características de los accidentes registrados durante dieciséis años en un hospital general con sangre o fluidos biológicos procedentes de pacientes VIH positivos, determinar las tasas de exposición accidental en las diferentes categorías profesionales y comprobar el seguimiento realizado por los trabajadores del protocolo de accidentes establecido.

Métodos: Estudio descriptivo en un hospital general de Madric durante el período 1986 a 2001, de los accidentes con presencia de material biológico procedente de personas con serología VIH positiva. Se han estudiado variables del profesional accidentado relacionadas con persona, lugar y tiempo, además de las serologías al inicio y durante el seguimiento protocolizado.

Resultados: Durante el período de estudio se declararon 550 accidentes con fuente VIH positiva. La media fue de 34,4 de accidentes por año. La tasa de exposición fue de 7,5 por cada 1.000 trabajadores-año. El colectivo profesional con mayor frecuencia de accidentes fue el personal de enfermería $(54,4 \%)$. Las lesiones percutáneas fueron las más frecuentes $(80,2 \%)$. La tasa media de exposición ha sido de 2,6 por cada 100 camas-año. Las zonas anatómicas más afectadas fueron los dedos de la mano $(75,6 \%)$. El 53,6\% de los accidentados finalizó el seguimiento serológico, sin registrarse ninguna seroconversión.

Conclusiones: Durante los dieciséis años de estudio, la incidencia anual de accidentes con fuente VIH positiva fue en aumento desde los 27 accidentes declarados en 1986 hasta los 60 accidentes en 1990 , con una tendencia descendente desde ese momento hasta contabilizarse 12 accidentes en el año 2001

Palabras clave: Anticuerpos anti-VIH. Accidentes de trabajo. Hospitales. Personal sanitario.

\section{Correspondencia:}

Dra. Aurelia García de Codes

Servicio de Medicina Preventiva. Hospital Universitario "12 de Octubre"

Carretera de Andalucía s/n

28041 Madrid

Correo electrónico: jrjp@medynet.com

\section{ABSTRACT}

Accidents Involving Exposure to HIV-Contaminated Biological Material among Workers at a Third-Level Hospital in Madrid (1986-2001)

Background: Human Immunodeficiency Virus (HIV) is an occupational hazard among healthcare professionals accidentally contaminated with HIV-positive blood. This study is aimed at describing the characteristics of the accidents involving blood of HIVpositive patients recorded over a sixteen-year period at a general hospital.

Methods: Epidemiological study of the accidents reported in 2001 involving biological material from an HIV-positive source by the healthcare personnel of a general hospital throughout the 19862001 period entailing the presence of biological material from HIV positive serology individuals. Individual, time and place-related variables, in addition to the initial serologies and those throughout the protocolized follow-up were studied for those individuals involved in these accidents.

Results: A total 550 accidents entailing an HIV-positive source were reported. The average number of accidents was $34.4 / y e a r$. The accidental exposure rate for the period under study was $7.5 / 1000$ workers /year. The professional group showing the highest accident rate was the nursing staff $(54.4 \%)$. Percutaneous injuries were the most frequent $(80.2 \%)$. The mean exposure rate was $2.6 / 100$ beds/year. The anatomical areas involved to the greatest degree were the fingers $(75.6 \%)$. A total $53.4 \%$ of those injured completed the serological follow-up without having shown any seroconversion.

Conclusions: Throughout the sixteen-year period under study, the annual incidence of accidents involving an HIV-positive source increased from the 27 accidents reported in 1986 to the 60 accidents reported in 1990, there having been a downward trend as of that point in time, to the point of 12 accidents having been recorded in 2001.

Key words: HIV. Injuries. Hospital. Healthcare workers. 


\section{INTRODUCCIÓN}

Desde hace años se acepta que el riesgo biológico es, sin duda, el más frecuente entre los riesgos laborales de los trabajadores de la salud y, dentro de este grupo, las inoculaciones accidentales son las que generan una mayor angustia y percepción de riesgo en este colectivo ${ }^{1}$.

Se entiende por exposición accidental ocupacional las inoculaciones parenterales (pinchazos, cortes, rasguños) y el contacto con membranas mucosas o piel no intacta (lesiones o dermatitis) de sangre, tejidos u otros fluidos corporales potencialmente contaminados; también deben valorarse los contactos con piel intacta en tiempo prolongado, con sangre u otros fluidos potencialmente infecciosos, que impliquen un área extensa, así como el contacto directo con muestras de laboratorio ${ }^{2}$.

El principal riesgo asociado a este tipo de accidentes es la probabilidad de transmisión sérica de tres microorganismos: el virus de la hepatitis B (VHB), el virus de la hepatitis C (VHC) y el virus de la inmunodeficiencia humana $(\mathrm{VIH})^{2-4}$. La vía percutánea es la forma de exposición más frecuente y de mayor riesgo ${ }^{5-7}$, seguida por la exposición a través de las mucosas ${ }^{2,8}$. La transmisión por vía cutánea, aunque no ha sido cuantifica$\mathrm{da}^{8,9}$, se considera excepcional, habiendo disminuido notablemente este tipo de exposiciones tras la introducción de precauciones universales ${ }^{10-12}$.

La descripción del primer caso de sida de transmisión ocupacional en una enfermera en diciembre de 1984 fue un factor fundamental en la sensibilización del personal sanitario sobre los riesgos en estos profesionales. Los resultados de los estudios prospectivos realizados en trabajadores sanitarios que han sufrido una exposición accidental a sangre o fluidos corporales procedentes de pacientes infectados con VIH, permiten afirmar que el riesgo de transmisión después de una exposición percutánea ocupacional es del 0,3\% (IC95\%: 0,2-0,5\%) y muy inferior en las exposiciones en mucosas en las que el riesgo es del 0,09\% (IC95\%:0,006$0,5 \%)^{6,13-16}$.

El riesgo de exposición a VIH, para los trabajadores está principalmente relacionado con la prevalencia de infección VIH en los pacientes de un área específica ${ }^{17}$; los cuatro factores que tras un accidente incrementan el riesgo de los trabajadores de adquirir infección por VIH son: herida profunda, aguja usada en vena o arteria del enfermo, sangre visible en el material causante de accidente y paciente fuente con enfermedad terminal ${ }^{14,18}$.

En relación con el riesgo de transmisión de VIH para los trabajadores del medio sanitario han ido apareciendo en la bibliografía médica numerosos estudios prospectivos de exposiciones accidentales con material biológico, presentando muchos de ellos problemas de infradeclaración en todas las categorías profesionales. Entre estas destaca el colectivo de médicos, debido a la «falta de tiempo», el desconocimiento del sistema de declaración, la no percepción de riesgo, desconfianza en la confidencialidad de los resultados, y la posibilidad de discriminación personal y profesional en caso de ser encontrados VIH positivos ${ }^{19,20}$.

El objetivo de nuestro estudio es describir las características de los accidentes registrados durante dieciséis años en un hospital general con sangre o fluidos biológicos procedentes de pacientes VIH positivos, determinar las tasas de exposición accidental en las diferentes categorías profesionales y comprobar el seguimiento realizado por los trabajadores del protocolo de accidentes establecido.

\section{SUJETOS Y MÉTODOS}

Estudio epidemiológico de cohortes de los accidentes con material biológico de 
fuente VIH positiva, declarados por los trabajadores del Hospital Universitario 12 de Octubre de Madrid, en el período comprendido entre 1986 y 2001. Se trata de un hospital de tercer nivel dotado con 1.300 camas, asumiendo que en todas ellas pueden ingresar enfermos con infección por VIH.

El Servicio de Medicina Preventiva tiene establecido desde el año 1985 un sistema de vigilancia activa frente al $\mathrm{VIH}$, que incluye el control de los accidentes acaecidos en el hospital.

El trabajador accidentado comunica el accidente a la Unidad de Personal y a nuestro Servicio para poder adoptar las medidas administrativas y profilácticas adecuadas. Se cumplimenta una «ficha epidemiológica» para conocer la serología del paciente fuente y otros datos de interés, iniciándose el protocolo de seguimiento establecido al respecto. En ese primer momento se extrae al accidentado una muestra de sangre y posteriormente se repite la extracción al mes, a los tres, a los seis y a los doce meses del accidente, para determinar por enzimoinmunoanálisis (ELISA) la presencia o ausencia de anticuerpos frente al VIH.

Las variables estudiadas, relacionadas con el accidente, recogidas en la ficha epidemiológica de cada accidentado son: temporales (fecha de exposición); personales: sexo (hombre, mujer), edad (agrupada en los siguientes grupos etarios:18-25 años; 26-35; 36-45; 46-55; mayores de 55); categoría laboral (auxiliar de enfermería, Ayudante técnico sanitario/Diplomado Universitario en Enfermería (ATS/DUE), médico de plantilla, médico residente (MIR), técnico de laboratorio (TEL), técnico de radiología (TER), celador, matrona y fisioterapeuta); tipo de lesión percutánea (punción/corte), cutáneomucosa (salpicadura); lugar de la exposición (plantas de hospitalización, área quirúrgica, laboratorios, UCIs, urgencias, diálisis, radiología/medicina nuclear, consulta y áreas de circulación); turno de traba- jo (mañana, tarde, noche); agente causante de la exposición (instrumental, materia orgánica) y localización anatómica de la lesión (cara, tronco, extremidades superiores, extremidades inferiores); serologías realizadas.

La población media anual por categorías, proporcionada por la unidad de personal de nuestro centro, se agrupa de la siguiente manera: 1.278 auxiliares de enfermería (1.264 mujeres y 14 hombres), 1.667 ATS/DUEs (1.337 mujeres y 330 hombres), 650 médicos de plantilla (227 mujeres y 423 hombres), 400 MIR (260 mujeres y 140 hombres), 46 TEL (42 mujeres y 4 hombres), 47 TER (38 mujeres y 9 hombres), 344 celadores (56 mujeres y 288 hombres), 57 matronas (56 mujeres y 1 hombre) y 70 fisioterapeutas (37 mujeres y 33 hombres), lo que representa un total de 4.559 trabajadores potencialmente expuestos cada año (3317 mujeres y 1.242 hombres) que, considerados los dieciséis años del estudio, suponen un total de 72.944 trabajadores-año de seguimiento (53.072 mujeres-año y 19.872 hombres-año). El seguimiento a cada trabajador para la detección de una posible seroconversión se ha realizado durante los 12 meses de protocolo; no se ha tenido en cuenta la profilaxis postexposición ocupacional con antirretrovirales ofertada desde 1998.

Como indicador del riesgo de exposición se ha calculado la tasa de exposición por cada 100 camas-año y la tasa de exposición accidental (TEA) para el período 19862001, siendo el numerador los accidentes registrados en ese intervalo y el denominador el total de trabajadores potencialmente expuestos en esos años.

Los resultados obtenidos de la medición de las distintas variables se expresan bien en porcentajes, bien como media y su desviación estándar. La comparación de variables cualitativas y las tasas observadas entre los diferentes grupos se realiza mediante chicuadrado, estimando las correcciones cuan- 
do estaban indicadas. Para dicho análisis se ha empleado el programa estadístico EPI Info 6.2 , y se ha considerando significativa una $\mathrm{p}<0,05$.

\section{RESULTADOS}

Entre enero de 1986 y diciembre de 2001 se declararon en nuestro servicio un total de 550 accidentes por exposición a sangre de pacientes con determinación de anticuerpos positiva frente a VIH (ELISA). Durante el período de estudio el número de accidentes declarados ha oscilado entre 27 exposiciones en 1986 y 12 en 2001, con un máximo de 60 accidentes en 1990 (figura 1). La media de accidentes por año fue 34,4 (DE 14,8).

Por sexo, 412 (74,9\%) accidentes fueron declarados por mujeres y 138 por hombres $(25,1 \%)$. La tasa de exposición accidental fue de 7,5 por cada 1.000 trabajadores-año (mujeres 7,8 y hombres 6,9) (tabla 1).

La edad media del accidentado ha sido 34,7 años (DE 9,4), siendo los trabajadores del grupo de 26-35 años los que más se acci-

Figura 1

Distribución de los accidentes por año. Tasa de exposición por 100 camas-año

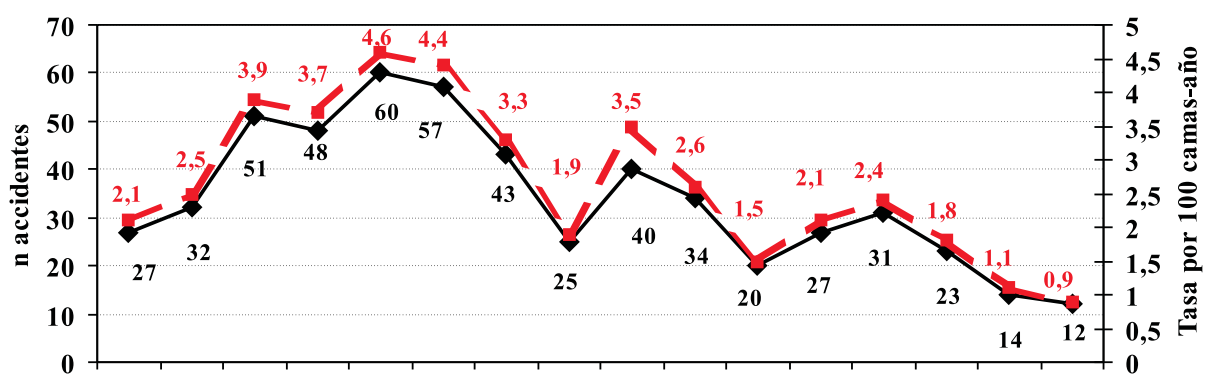

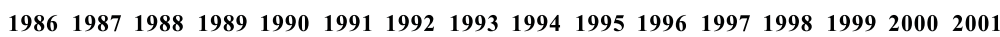

Años 1986-2001

$\longrightarrow N^{0}$ accidentes $\longrightarrow-$ Tasa por 100 camas-año

Tabla 1

Distribución de los accidentes y Tasas de exposición accidental (TEA) por categoría profesional y sexo

\begin{tabular}{|l|c|c|c|c|}
\hline Categoría profesional & $\begin{array}{c}\text { Exposiciones en } \\
\text { mujeres }\end{array}$ & $\begin{array}{c}\text { Tasa por 1000 } \\
\text { mujeres-año }\end{array}$ & $\begin{array}{c}\text { Exposiciones en } \\
\text { hombres }\end{array}$ & $\begin{array}{c}\text { Tasa por 1000 } \\
\text { Hombres-año }\end{array}$ \\
\hline Auxiliar de enfermería & 92 & 4,5 & 2 & 8,9 \\
\hline ATS/DUE & 247 & 11,5 & 48 & 6,1 \\
\hline Médico de plantilla & 15 & 4,1 & 45 & 14,7 \\
\hline Médico residente (MIR) & 36 & 8,6 & 33 & 15,6 \\
\hline Técnico laboratorio (TEL) & 6 & 8,9 & 1 & 1,9 \\
\hline Técnico radiología (TER) & 4 & 6,6 & 2 & - \\
\hline Celador & 3 & 3,3 & 7 & - \\
\hline Matrona & 6 & 6,7 & - & 6,9 \\
\hline Fisioterapeuta & 3 & 5,1 & - & $138(25,1 \%)$ \\
\hline TOTAL & $412(74,9 \%)$ & 7,8 & & \\
\hline
\end{tabular}


Tabla 2

Distribución de los accidentes por grupos de edad

\begin{tabular}{|l|c|c|}
\hline Grupos de edad & n accidentes & $\%$ \\
\hline $18-25$ años & 79 & 14,4 \\
\hline $26-35$ años & 244 & 44,4 \\
\hline $36-45$ años & 152 & 27,6 \\
\hline $46-55$ años & 54 & 9,8 \\
\hline$>55$ años & 21 & 3,8 \\
\hline TOTAL & 550 & $100 \%$ \\
\hline
\end{tabular}

Tabla 3

Distribución de los accidentes totales por categoría profesional. Tasas de exposición accidental (TEA) por 1000 trabajadores-año

\begin{tabular}{|l|c|c|c|}
\hline Categoría Profesional & N exposiciones & \% & $\begin{array}{c}\text { Tasa por 1000 } \\
\text { trabajadores-año }\end{array}$ \\
\hline Auxiliar de enfermería & 94 & 17,1 & 4,6 \\
\hline ATS/DUE & 295 & 53,6 & 11,1 \\
\hline Médico de plantilla & 60 & 10,9 & 5,8 \\
\hline Médico residentes (MIR) & 69 & 12,5 & 10,8 \\
\hline Técnico laboratorio (TEL) & 7 & 1,3 & 8,5 \\
\hline Técnico radiología (TER) & 6 & 1,8 & 1,8 \\
\hline Celador & 6 & 1,1 & 6,6 \\
\hline Matrona & 3 & 0,5 & 2,7 \\
\hline Fisioterapeuta & 550 & $100 \%$ & 7,5 \\
\hline TOTAL & & & \\
\hline
\end{tabular}

dentaron $(244 ; 44,4 \%)$ (tabla 2). Las mujeres tenían una edad media de 34,7 (DE 9,5) y los hombres de 34,6 años (DE 9,1).

Por categoría profesional han declarado accidentes 295 ATS/DUEs (53,6\%), 94 auxiliares de enfermería $(17,1 \%), 69$ médicos residentes $(12,5 \%) 60$ médicos de plantilla $(10,9 \%)$, correspondiendo el resto $(5,8 \%)$ a otras categorías laborales. El colectivo profesional con mayor tasa de exposiciones accidentales ha sido el de ATS/DUE (TEA: 11,1 por 1000 enfermeras-año), seguido de los médicos residentes (TEA: 10,8 por 1000 residentes-año) y los técnicos de laboratorio (TEA: 9,5 por 1000 técnicos-año) (tabla 3). La tasa de exposición accidental más elevada entre las mujeres correspondió al personal de enfermería (11,5/1000 mujeres ATS/DUE-año) y entre los hombres, los técnicos de laboratorio (15,6 / 1000 hombresTEL-año) y médicos residentes (14,7 / 1000 hombres-MIR-año).

El tipo de lesión más frecuente ha sido la percutánea (punciones/cortes) $(80,2 \%)$; las 
Tabla 4

Distribución de los accidentes por vía percutánea y cutaneomucosas por categoría profesional. Tasas de exposición accidental (TEA) por 1000 trabajadores-año

\begin{tabular}{|l|c|c|c|c|}
\hline Categoría profesional & $\begin{array}{c}\text { Exposiciones } \\
\text { Percutáneas } \\
\mathbf{n}(\%)\end{array}$ & $\begin{array}{l}\text { E. percutáneas } \\
\text { Tasa por 1000 } \\
\text { trabajadores-año }\end{array}$ & $\begin{array}{l}\text { Exposiciones } \\
\text { Cutaneomucosas } \\
\mathbf{n}(\%)\end{array}$ & $\begin{array}{l}\text { E. cutaneomucosas } \\
\text { Tasa por 1000 } \\
\text { trabajadores-año }\end{array}$ \\
\hline Auxiliar de enfermería & $71(16,1 \%)$ & 3,5 & $23(21,1 \%)$ & 1,1 \\
\hline ATS/DUE & $240(54,4 \%)$ & 9,0 & $55(50,5 \%)$ & 2,1 \\
\hline Médico de plantilla & $53(12,0 \%)$ & 5,1 & $7(6,4 \%)$ & 0,7 \\
\hline Médico residentes (MIR) & $55(12,5 \%)$ & 8,6 & $14(12,8 \%)$ & 2,2 \\
\hline Técnico laboratorio (TEL) & $3(0,7 \%)$ & 4,1 & $4(3,7 \%)$ & 5,4 \\
\hline Técnico radiología (TER) & $6(1,4 \%)$ & 8,0 & - & 0,4 \\
\hline Celador & $8(1,8 \%)$ & 1,4 & $2(1,8 \%)$ & 2,2 \\
\hline Matrona & $4(0,9 \%)$ & 4,4 & $2(1,8 \%)$ & 1,8 \\
\hline Fisioterapeuta & $1(0,2 \%)$ & 0,9 & $109(100 \%)$ & 1,5 \\
\hline TOTAL & $441(100 \%)$ & 6,0 & & - \\
\hline
\end{tabular}

exposiciones cutáneo-mucosas han supuesto el $19,8 \%$ restante. En las exposiciones percutáneas, la categoría profesional con mayor TEA fue la de ATS/DUE (9,0 exposiciones por 1000 ATS/DUE-año), seguida por los médicos residentes $(8,6$ exposiciones por 1000 residentes-año); en las exposiciones cutáneomucosas, la TEA más elevada la presentaron los técnicos de laboratorio $(5,4$ exposiciones por cada 1000 técnicos-año) (Tabla 4).

La tasa media de exposiciones accidentales por cada 100 camas-año en el período de estudio ha sido de 2,6 , siendo la tasa más elevada en el año 1990 (4,6 exposiciones por 100 camas-año) (figura 1).

Los lugares de trabajo con mayor accidentabilidad fueron las plantas de hospitalización $(36,7 \%)$, quirófanos $(20,5 \%)$, UCIs $(13,1 \%)$, laboratorios $(10,9 \%)$ y urgencias $(10 \%)$; el resto $(8,8 \%)$ se corresponde con otros lugares del hospital.

En el turno de mañana se accidentaron 372 trabajadores $(67,6 \%)$, en el de la tarde $111(20,2 \%)$ y $67(12,2 \%)$ por la noche. El agente causal del accidente fue el instrumen- tal médico en 437 ocasiones $(79,5 \%)$, seguido de materia orgánica con 109 casos $(19,8 \%)$. Las zonas anatómicas más afectadas fueron los dedos con 416 casos $(75,6 \%)$, seguido de ojos y cara (65 casos $(11,8 \%)$.

Los 550 trabajadores accidentados con serología basal VIH negativo en el momento del accidente, se realizaron seguimiento analítico al mes $485(88,2 \%)$, a los tres meses $439(79,8 \%)$, a los seis $380(69,1 \%)$ y al año $295(53,6 \%)$ trabajadores, no registrándose ninguna seroconversión. El 46,4\% de los trabajadores no completó el seguimiento anual.

\section{DISCUSIÓN}

Durante los dieciséis años de estudio, la incidencia anual de accidentes con fuente VIH positiva fue en aumento, desde los 27 accidentes declarados en 1986 hasta los 60 accidentes en 1990, con una tendencia descendente desde ese momento hasta contabilizar 12 accidentes en el año 2001, y una media de 34,4 accidentes por año.

Debemos tener en cuenta que, aunque en España la incidencia anual de casos contabi- 
lizados de sida en la población aumentó hasta 1994, la extensión de los tratamientos antirretrovirales de alta eficacia dio lugar a una caída del $28 \%$ en la incidencia entre 1996 y 1997, continuando la misma tendencia en los años siguientes con un ritmo más suave $^{21}$. En consecuencia, debido a la disminución de la morbi-mortalidad de estos enfermos, aunque el número de pacientes ha aumentado, se ha podido producir un desplazamiento de las hospitalizaciones hacia las consultas externas y la atención extrahospitalaria. La alta eficacia de los nuevos tratamientos ha disminuido de forma marcada la complejidad de los cuidados requeridos por estos pacientes, por lo que el número y tipo de procedimientos que se les realiza y que suponen un riesgo de accidente para el personal sanitario es menor que hace unos años. Esto ha podido contribuir a una disminución en el número de accidentes con fuente VIH positiva.

En España y según datos del Estudio y seguimiento del riesgo biológico en personal sanitario realizado por la Sociedad Española de Medicina Preventiva (EPINETAC) ${ }^{22}$, que recoge los accidentes biológicos de sesenta y cinco hospitales españoles durante los años 1998-2000, parece observarse un ligero descenso en la prevalencia de serología VIH positiva en los pacientes fuente implicados en las exposiciones declaradas, disminuyendo de 5,9\% en 1998 a $4,6 \%$ en el año 2000. Otros autores han encontrado una prevalencia aún menor de fuente positiva para el VIH $(2,4 \%$ de los pacientes) en una serie de accidentes biológicos declarados en hospitales italianos ${ }^{23}$. En ambos casos, esta disminución podría relacionarse con una disminución del riesgo VIH en los accidentes con sangre u otros fluidos.

Por sexo, como en la mayoría de los estudios publicados ${ }^{22-24}$, las mujeres declaran más accidentes que los hombres $(74,9 \%$ y $25,1 \%$ respectivamente), como se corresponde con la estructura de la población tra- bajadora, no presentando diferencias estadísticamente significativas.

Los primeros años de vida laboral juegan un papel importante y negativo en la incidencia de la exposición. Así, en nuestro estudio, los accidentados tenían una edad media de 34,7 años y más de un 44\% correspondían al grupo etario de 26-35 años. En otro estudio $^{25}$ realizado en este mismo Servicio de Medicina Preventiva sobre accidentes biológicos con fuente positiva para VIH entre 1985 y 1988, más de un 60\% de los accidentados eran menores de 36 años. Otros autores describen el alto riesgo de exposición biológica para médicos en los primeros años de ejercicio profesional. Los accidentes parecen producirse con más frecuencia en los cinco primeros años de trabajo, lo que puede ser indicativo de una menor destreza en la manipulación del material, aunque también puede ser debido a una diferente percepción del riesgo, de tal forma que se declararían con más frecuencia los accidentes al inicio de la vida laboral e iría disminuyendo la declaración conforme aumenta el tiempo trabajado y decrece la percepción del riesgo ${ }^{9,26,27}$.

En la mayoría de los estudios sobre accidentes biológicos en general, la categoría profesional que más accidentes declara es la de enfermería $a^{9,22,25,28}$, pero en trabajos que hacen referencia sólo a exposiciones ocupacionales con fuente positiva a cualquier virus (VHB, VHC o VIH) la tasa de exposición más alta la presenta el personal médi$\mathrm{co}^{29}$.

En nuestro estudio los ATS/DUE han declarado más de un 53\% de los accidentes, seguidas de las auxiliares de enfermería $(17,1 \%)$ y de los médicos residentes $(12,5 \%)$. Los ATS/DUE se han accidentado más que los auxiliares de enfermería y los médicos de plantilla $(\mathrm{p}<0,01)$ y los médicos residentes más que los médicos de plantilla $(\mathrm{p}<0,01)$. En exposiciones percutáneas, la tasa de accidentabilidad más ele- 
vada la presentaron los ATS/DUE (9/1000 ATS/DUE-año) seguidos de los médicos residentes (8,6/1000-MIR-año); en las exposiciones cutáneomucosas fueron los técnicos de laboratorio el colectivo con mayor tasa de exposición (5,4 / 1000-TELaño), superior al resto de trabajadores sanitarios $(\mathrm{p}<0,05)$. Estos datos son similares a los obtenidos en otros estudios sobre riesgo biológico ${ }^{9,22}$.

Durante este período todos los trabajadores tuvieron una serología basal negativa y no se ha registrado ninguna seroconversión, ni en los trabajadores que se accidentaron antes de que se ofertara la profilaxis postexposición con antirretrovirales, ni en los que tomaron la medicación. Esto concuerda con la aceptación de que la mayoría de las exposiciones parenterales a VIH $(99,7 \%)$ no transmiten la infección y con que en la mayor parte de los estudios de accidentes biológicos no ha existido transmisión ocupacional de VIH, ya sea con o sin tratamiento antirretroviral postexposición $^{22,23,25,30}$.

Sin embargo, se debe recordar que en Estados Unidos hasta diciembre de 2001 se había confirmado la existencia de 57 casos documentados y 138 posibles de transmisión ocupacional de VIH en trabajadores sanitarios $^{31,32}$. En Europa se han confirmado 34 casos y aceptado otros 70 como casos posibles y en España se han documentado 5 casos de transmisión ocupacional de $\mathrm{VIH}^{33}$.

Tanto en Estados Unidos como en Europa el personal que más ha sufrido las consecuencias de una seroconversión confirmada de transmisión ocupacional de VIH es el de enfermería, seguida por los técnicos de laboratorio y los médicos ${ }^{31,33}$, que también son las que en nuestra serie tienen las mayores tasas de incidencia. Estas casuísticas no difieren de los primeros datos proporcionados por los Centers for Disease Control (CDC) de Atlanta ${ }^{34}$.
Los 550 profesionales accidentados con fuente positiva al VIH se realizaron el primer seguimiento analítico, al mes el 88,2\% y a los seis meses el 69,1\%. Otros autores ${ }^{24}$, describen en un registro de exposiciones ocupacionales a VIH de Estados Unidos cifras similares a las nuestras (seguimiento al mes del $91 \%$ de los trabajadores y a los 6 meses del 62\%).

Un $11,8 \%$ de trabajadores no se realizaron ningún control analítico posterior al accidente. En el estudio anterior realizado en nuestro servicio, este porcentaje era de un $8,4 \%{ }^{25}$, lo que se puede interpretar como una despreocupación o falta de percepción de riesgo similar a lo largo de este tiempo. Por categorías profesionales, más de un $18 \%$ de los médicos de plantilla que declararon un accidente con fuente VIH positiva sólo se realizaron la primera analítica.

La categoría profesional que menos finalizó el seguimiento analítico (control a los doce meses) fueron los médicos residentes (un $68,1 \%$ no se lo realizaron), siendo los técnicos de radiología los más concienciados (83,3\% si se lo realizaron).

Para el trabajador, documentar ausencia de infección en el momento de la exposición (serología basal) es muy importante en el caso de que ocurriera una seroconversión posterior. Serologías secuenciales (4-6 semanas, 3 y 6 meses) son muy útiles para aliviar la ansiedad del accidentado, documentar seronegatividad y, rara vez para diagnosticar precozmente infección VIH. La seroconversión VIH ocurre en los tres primeros meses en más de la mitad de las infecciones ocupacionales y en los seis meses postexposición en la gran mayoría de los $\operatorname{casos}^{35,36}$.

Durante los últimos 20 años se han producido cambios que pueden influir en el riesgo de infección ocupacional por VIH. El aumento de los conocimientos de los mecanismos de trasmisión del VIH y cómo ocurre 
la exposición, han conducido a la mejora de la seguridad laboral de los trabajadores sanitarios, con la elaboración de guías para el control de la infección y el rediseño de los materiales cortantes/punzantes. Cuando se aplican adecuadamente algunas de estas medidas son efectivas en reducir la exposición a sangre, disminuyendo potencialmente el riesgo de infección ocupacional por VIH. La mejora en la atención postexposición con antirretrovirales también puede haber aumentado los efectos preventivos para los trabajadores sanitarios, aunque su medición ha sido difícil de determinar ${ }^{32,37}$.

La protección ofrecida por la profilaxis postexposición ocupacional al VIH no es absoluta, y evitar la exposición a sangre continúa siendo la principal medida para prevenir la transmisión ocupacional de $\mathrm{VIH}^{38}$.

Algunas exposiciones podían haber sido prevenidas aplicando las precauciones universales. Desde 1987, cuando estas recomendaciones fueron publicadas ${ }^{10,39}$ advirtiendo del riesgo de encapuchado de las agujas, no se ha documentado ningún caso de infección VIH como consecuencia de un accidente por encapuchar una aguja. Sin embargo, accidentes relacionados con la colocación o eliminación de material punzante en lugares inseguros o inadecuados todavía son relativamente frecuentes y causa de algunos de los casos más recientes de transmisión ocupacional de $\mathrm{VIH}^{32,40}$.

El uso de dispositivos médicos de bioseguridad aumenta la seguridad de los trabajadores sanitarios ${ }^{41}$, pero debe ser considerado como un componente de un programa más extenso para prevenir la transmisión ocupacional de VIH en el medio sanitario. El conjunto de todas las medidas de control administrativas y de ingeniería es, junto con el uso de equipos de protección individual y prácticas de trabajo más seguras, la manera más efectiva de prevenir la exposición ocupacional al VIH.

\section{BIBLIOGRAFIA}

1. Leibowitz S, Greenwald L, Cohen I, Litwins J. Serum hepatitis in a blood banck worker. JAMA $1949 ; 140: 1331-3$.

2. Gerberding JL. Management of occupational exposures to blood-borne viruses. N Engl J Med 1995;332(7):444-51.

3. CDC. Public Health Service. Guidelines for the Manegement of Health-Care Workers Exposures to HIV and Recommendations for Postexposure Prophylaxis. MMWR 1998;47(RR-7):1-34.

4. CDC.Update U.S. Public Health Service. Guidelines for the Manegement of Occupational Exposures to $\mathrm{HBV}, \mathrm{HCV}$, and HIV and Recommendations for Postexposure Prophylaxis. MMWR 2001;50(RR-11):1-52.

5. Haro AM, Sacristán A, Sáez MC. Estandarización de los criterios para la profilaxis postexposición ocupacional al virus de la inmunodeficiencia humana. Rev Clin Esp 1999;199(4):233-8.

6. Bell DM. Occupational Risk of Human Immunodeficiency Virus Infection in Healthcare Workers: An Overview. Am J Med 1997;102(suppl 5B):9-15.

7. de Juanes JR. Problemática de los accidentes con sangre y/o derivados en un hospital general. Cinco años de seguimiento. Rev Esp Microbiol Clin 1986;1(5): 317-21.

8. Fahey BJ, Koziol DE, Banks SM. Frecuency of Nonparenteral Occupational Exposures to Blood and Body Fluid Before and After Universal Precautions Training. Am J Med 1991;90:145-53.

9. Beekmann SE, Vaughn TE, McCoy KD, Ferguson KJ, Torner JC, Woolson RF, et al. Hospital Bloodborne Pathogens Programs: Program Characteristics and Blood and Body Fluid Exposure Rates. Infect Control Hosp Epidemiol 2001;22(2):73-82.

10. CDC.Update Universal Precaution for Prevention of Transmission of Human Immunodeficency Virus, Hepatitis B Virus, and other Bloodborne Pathogens in Health-Care Setting. MMWR 1988;37:377-88.

11. Riddell LA, Sherrard J. Blood-borne virus infection: the occupational risk. Int J STD AIDS 2000;11(10):632-9.

12. Beltrami EM, Willians IT, Shapiro CN, Chamberland ME. Risk and management of blood-borne 
infections in health care workers. Clin Microbiol Rev 2000;13(3):385-407.

13. Cardo DM, Culver DH, Ciesielski CA, Srivastava PU, Marcus R, Abiteboul D, et al. A Case-Control Study of HIV Seroconvesion in Health Care Workers after Percutaneous Exposure. N Engl J Med 1997;337(21):1485-90.

14. Ippolito G, Puro V, Heptonstall J, Jagger J, De Carli G, Petrosillo N. Occupational human immunodeficiency virus infection in health care workers: worldwide cases through september 1997. Clin Infect Dis 1999; 28 (2):365-83.

15. Puro V, De Carli G, Petrosillo N, Ippolito G. Risk of Exposure to Bloodborne Infection for Italian Healthcare Workers, by Job Category and Work Area. Infect Control Hosp Epidemiol 2001; 22(4):206-10.

16. Gerberding JL. Occupational exposure to HIV in Health Care Settings. N Engl J Med 2003; 348(9):826-33.

17. Beltrami EM, Kozak A, Williams IT, Saekhou AM, Kalish ML, Nainan OV, et al. Transmission of HIV and hepatitis $\mathrm{C}$ virus from a nursing home patient to a health care worker. Am J Infect Control 2003; 31(3):168-75.

18. Moran JG. Emergency departament management of blood and body fluid exposures. Ann Emerg Med 2000;35:47-62.

19. Rabaud C, Zanea A, Mur JM, Blench MF, Dazy D, May T, et al. Occupational Exposure to Blood:Search for a Relation Betweeen Personality and Behavior. Infect Control Hosp Epidemiol 2000;21(9): 564-74.

20. Magnione CM, Gerberding JL, Cummings SR. Occupational exposure to HIV: frequency and rates of underreporting of percutaneous and mucocutaneous exposures by medical housestaff. Am J Med 1991;90: 85-91.

21. Centro Nacional de Epidemiología. Vigilancia Epidemiológica del SIDA en España. Situación a 31 de diciembre de 2002. Bol Epidemiol Semanal 2002;10(25): 269-76.

22. Campins M, García de Codes A. Exposiciones ocupacionales a sangre y material biológico en los trabajadores sanitarios (EPINETAC 1998-2000) En: Campins M y Hernández MJ, ed. Estudio y seguimiento del riesgo biológico en el personal sanitario. Madrid 2002: 31-72.
23. Baldo V, Floreani A, Dal Vecchio L, Cristofoletti M, Carletti M, Majori S, et al. Occupational Risk of Blood-Borne Viruses in Healthcare Workers: A 5Year Surveillance Program. Infect Control Hosp Epidemiol 2002;23(6): 325-7.

24. Wang SA, Panlilio AL, Doi PA, White AD, Stek M, Saah A. Experience of Healthcare Workers Taking Postexposure Prophylaxis After Occupational HIV Exposures: Finding of the HIV Postexposure Prophylaxis Registry. Infect Control Hosp Epidemiol 2000;21(12): 780-5.

25. de Juanes JR, Fuertes A, Lago E, Dávila M. Síndrome de inmunodeficiencia adquirida y accidentes en el personal sanitario. Tres años de seguimiento. Rev Esp Microbiol Clin 1988;3(6): 399403.

26. de Juanes JR, Lago E, García de Codes A, Arrazola MP, Aragón AJ, Dávila FD, et al. Exposición de los cirujanos de un hospital general a agentes biológicos, a través de accidentes con sangre. Cirugía Española 1995; 57(4): 349-54.

27. Gilk CF, Wilkinson D. Reducing the risk of nosocomial HIV infection in British health workers working overseas: role of post-exposure prophylaxis. BMJ 1998;316(7138): 1158-60.

28. de Juanes JR, Villagrasa JR, Domínguez V, Rivera JM, Lago E. Estudio de los accidentes laborales en un hospital general 1981-1989. Med Seguridad Trabajo1993;159: 5-20.

29. Blázquez RM, Moreno S, Menasalvas A, Guerrero C, Novoa A, Segovia M. Exposición a patógenos hemáticos en el personal sanitario. Enferm Infecc Microbiol Clin 2001;19: 156-60.

30 Sistrom MG, Coyner BJ, Gwaltney JM, Farr BM. Frequency of Percutaneous Injuries Requiring Postexposure Prophylaxis for Occupational Exposure to Human Immunodeficiency Virus. Infect Control Hosp Epidemiol 1998;19(7): 504-6.

31. CDC. Surveillance of Healthcare Personnel with HIV/SIDA, as of December 2001. (consultado en Julio 2003) Disponible en: http://www.cdc.gov/hiv /pubs/facts/hcwprev.htm

32. Do AN, Ciesielski CA, Metler RP, Hammett TA, Li J,Fleming PI. Occupationally Acquired Human Immunodeficiency Virus (HIV) Infection: National Case Surveillance Data During 20 years of the HIV Epidemic in the United States. Infect Control Hosp Epidemiol 2003; 24(2): 86-96.

33. Avila JA, Forcada JA. Infección por VIH en profesionales de la salud. En: Forcada JA ed. Guía de 
prevención del riesgo biológico para profesionales de enfermería. Madrid 2003.p. 23-31.

34. Marcus R. Surveillance of health care workers exposed to blood from patients infected with the human immunodeficiency virus. N Eng J Med 1988;319: 1118-27.

35. Gerberding JL. Occupational HIV infection. AIDS 1997;11(suppl A):S57-60.

36. Gerberding JL. Postexposure prophylaxis for HIV. Adv Exp Med Biol 1999;458: 213-22.

37. Henderson DK. HIV Postexposure Prophylaxis in the 21 st Century. Emerg Infect Dis 2001;7(2): 254 8

38. Beltrami EM, Luo CHL, de la Torre N, Cardo DM Transmission of Drug-Resistant HIV After an Occupational Exposure Despite Postexposure
Prophylaxis With a Combination Drug Regimen. Infect Control Hosp Epidemiol 2002; 23(6): 345-8.

39. CDC. Recommendations for prevention of HIV transmission in health-care settings. MMWR 1987; 36 (suppl. 2S): 3S-18.

40. Mendelson MH, Lin-Chen BY, Solomon R, Bailey E, Kogan G, Goldbold J. Evaluation of a Safety Resheathable Winged Steell Needle for Prevention of Percutaneous Injuries Associated with Intravascular-Access Procedures Among Healthcare Workers. Infect Control Hosp Epidemiol 2003; 24(2): 105-12.

41. Alvarado-Ramy F, Beltrami EM, Short LJ, Srivastava PU, Henry K, Mendelson M, et al. A Comprehensive Approach to Percutaneous Injury Prevention During Phlebotomy. Result of a Multicenter Study, 1993-1995. Infect Control Hosp Epidemiol 2003; 24(2): 97-104. 